\title{
The valuation of currency options by fractional Brownian motion
}

\author{
Foad Shokrollahi ${ }^{*}$ and Adem Kılıçman ${ }^{2}$
}

*Correspondence:

foad.shokrollahi@uva.fi

${ }^{1}$ Department

of Mathematics and Statistics,

University of Vaasa,

65101 Vaasa, Finland

Full list of author information

is available at the end of the

article

\section{Abstract}

This research aims to investigate a model for pricing of currency options in which value governed by the fractional Brownian motion model (FBM). The fractional partial differential equation and some Greeks are also obtained. In addition, some properties of our pricing formula and simulation studies are presented, which demonstrate that the FBM model is easy to use.

Keywords: Black-Scholes model, Fractional Brownian motion, Currency option, Option pricing

\section{Background}

A currency options refers to an agreement that gives right to the holder in order to buy or sell a defined amount of foreign currency at a constant exercise price on option exercise. American options are traded at any time before they expire. European options can be exercised only during a specified period immediately before expiration.

Black and Scholes (1973) put forward option pricing in 1973, which leads to be studied by different scholars (Dravid et al. 1993; Toft and Reiner 1997; Kwok 2000; Duan and Wei 1999) claim that two issues in stock markets are not able to be presented clearly in this option pricing introduced by $B S$ in accordance with Brownian motion $(B M)$. These concepts refer to asymmetric leptokurtic features and the volatility smile. In view of this, the BS model was improved by Garman and Kohlhagen (1983) in order to assess European currency options by considering two prominent features;

1. The market volatility estimation of an underlying as obvious as price and time functioning void of referring to the characteristics of a particular investor directly. These characteristics could be functions of utility, measures of risk aversion, or yield expecting.

2. Strategy of self-replicating or hedging.

However, it is significant to note that the mispriced currency options by the $G-K$ model were also substantiated in some studies (Cookson 1992). The most important reason of inappropriateness of this model for stock markets is the fact that the currencies are different from stocks so that the currency behavior is not captured by geometric Brownian motion (Ekvall et al. 1997). To tackle this problem regarding pricing currency options, 
various models were recommended by modifying the $G-K$ model (Rosenberg 1998; Sarwar and Krehbiel 2000; Bollen and Rasiel 2003; Shokrollahi and Kılıçman 2014a, b, 2015).

In view of this, the independency of logarithmic returns of the exchange rate was pointed out in all these studies along with the distribution of normal random variables. In addition, the empirical studies reveal that the logarithmic returns disseminations in the asset markets widely manifest excess kurtosis with high possibility of mass around the origin and in the tails, and indicate low possibility in the flanks in comparison with normal distribution of data. It means that financial return series include the properties, which are not normal, independent, linear and are self-similar, with heavy tails. Both autocorrelations and cross-correlations and also volatility clustering are considered to these properties.

In this regard, two fundamental features are considered in $F B M$ namely self-similarity and long-range dependence. Then, employing this process is more feasible in terms of capturing the behavior from financial asset (Carbone et al. 2004; Wang et al. 2010). Although, FBM is neither a semi-martingale nor a Markov process then, we are not able to employ the conventional stochastic calculus for analyzing it. Fortunately, the research interest in this field was re-encouraged by new insights in stochastic analysis based on the Wick integration (see Hu and Øksendal 2003) called the fractional-Ito-integral. Using this type of stochastic integration (Hu and Øksendal 2003) proofed that the fractional Black-Scholes market presents no arbitrage opportunity and is complete. However, Björk and Hult (2005) argued that the use of FBM in this context does not make much economic sense because, while Wick integration leads to no arbitrage, the definition of the corresponding self-financing trading strategies is quite restrictive and, for example, in the setup of Elliott and Van der Hoek (2003), the simple buy-and-hold strategy is not selffinancing. We noted that this arbitrage example in discrete-time does not, however, rule out the use of $F B M$ in finance. For example, Bender et al. (2007) showed that the existence of arbitrage opportunities depends very much on the definition of the admissible trading strategies. Furthermore, Bender et al. (2008) stated that the financial market does not admit arbitrage opportunities in a class of trading strategies if a continuous price process has the conditional small ball property and pathwise quadratic variation. Hence it is not too hard to accept this idea: some restrictions are sufficient to exclude arbitrage in the fractional Brownian market. Indeed, some authors have used the geometric FBM to capture the behavior of underlying asset and to obtain fractional Black-Scholes formulas for pricing options, including Necula (2002) and Bayraktar et al. (2004).

In this paper, the pricing formula is investigated for pricing currency options by using the $F B M$ model. Furthermore, we obtain risk neutral valuation model and fractional Black-Scholes equation. Some properties and numerical studies of our pricing formula are also analyzed. "Preparations" section deals with the definition and features of the $F B M$ process, and some results regarding quasi-conditional expectation are also investigated. In "Pricing model" section, option pricing formula for the European currency options is derived by the FBM model. "Properties of pricing formula" section describe the fractional differential equation and also investigates some Greeks of our model. We show empirical studies and simulation in "Numerical studies" section in order to indicate the efficiency of the FBM model and final section of the paper is "Conclusion". 


\section{Preparations}

This section deals with some assumptions and definitions which is needed for this study. For get more information you can see Necula (2002), Cheridito (2003), Mishura (2008), and $\mathrm{Hu}$ and Øksendal (2003).

Definition 1 A $F B M, B_{H}(t)$ with Hurst exponential $H \in(0,1)$ under the probability space $(\Omega, F, P)$ is a continuous Gaussian process with these features:

1. $B_{H}(0)=0$.

2. $E\left[B_{H}(t)\right]=0$ for all $t \geq 0$.

3. $\operatorname{cov}\left[B_{H}(t) B_{H}(s)\right]=\frac{1}{2}\left[t^{2 H}+s^{2 H}-|t-s|^{2 H}\right]$ for all $s, t \geq 0$.

4. If $H=\frac{1}{2}$ the $B_{H}(t)$ is equivalent to the Brownian motion.

Moreover, $E\left(B_{H}(t)-B_{H}(s)\right)^{2}=|t-s|^{2 H}$ and $B_{H}(t)$ is stationary increments and is $H$-self-similar in the sense that $B_{H}(c t)$ and $c^{H} B_{H}(t)$ have the similar distribution for every $c>0$. If $H>\frac{1}{2}$ the process $B_{H}(t)$ represents long-range correlation, by the following definition:

$$
\sum_{m=1}^{\infty} E\left[B_{H}(1)\left(B_{H}(m+1)-B_{H}(m)\right)\right]=\infty .
$$

Now, suppose $(\Omega, F, P)$ be a probability field such that $B_{t}^{H}$ is a $F B M$ with respect to $P$, Some results represented that is required for the following (see Necula 2002).

\section{Lemma 2 Consider the fractional differential equation}

$$
d S_{t}=\mu S_{t} d t+\sigma S_{t} d B_{t}^{H} \quad S_{0}=S
$$

then

$$
S_{t}=S_{0} \exp \left(\mu t+\sigma B_{t}^{H}-\frac{1}{2} \sigma^{2} t^{2 H}\right) .
$$

Lemma 3 Let $0<t<T$ and $\sigma \in \mathbb{C}$ then

$$
\widetilde{E}_{t}\left[e^{\sigma B_{T}^{H}}\right]=e^{\sigma B_{T}^{H}+\frac{\sigma^{2}}{2}\left(T^{2 H}-t^{2 H}\right)}
$$

where $\widetilde{E}_{t}$ shows the quasi-conditional expectation under risk-neutral measure.

Lemma 4 Suppose $f$ be a function such that $\widetilde{E}_{t}\left[f\left(B_{T}^{H}\right)\right]<\infty$. Thus for each $0<t \leq T$ and $\sigma \in \mathbb{C}$, we have

$$
\widetilde{E}_{t}\left[f\left(\sigma B_{T}^{H}\right)\right]=\int_{R} \frac{1}{\sqrt{2 \pi \sigma^{2}\left(T^{2 H}-t^{2 H}\right)}} \times \exp \left[-\frac{\left(x-\sigma B_{t}^{H}\right)^{2}}{2 \sigma^{2}\left(T^{2 H}-t^{2 H}\right)}\right] f(x) d x
$$


Let $f(x)=\mathbf{1}_{A}$ thus, the following corollary is obtained.

Corollary 5 Assume $A \in B(R)$. Therefore

$$
\widetilde{E}_{t}\left[\mathbf{1}_{A}\left(\sigma B_{T}^{H}\right)\right]=\int_{R} \frac{1}{\sqrt{2 \pi \sigma^{2}\left(T^{2 H}-t^{2 H}\right)}} \times \exp \left[-\frac{\left(x-\sigma B_{t}^{H}\right)^{2}}{2 \sigma^{2}\left(T^{2 H}-t^{2 H}\right)}\right] \mathbf{1}_{A}(x) d x .
$$

Assume $\theta, w \in R$. Then, this process considered

$$
Z_{t}^{*}=\theta\left(B_{t}^{H}\right)^{*}=\theta B_{t}^{H}+\theta^{2 H}, \quad 0 \leq t \leq T .
$$

According to the Girsanov formula, there is a measure $P^{*}$ such that $Z_{t}^{*}$ is a new FBM. We will denote $E_{t}^{*}\left[\right.$.] is a quasi-conditional expectation under $P^{*}$. Consider

$$
X_{t}=\exp \left(-\theta B_{t}^{H}-\frac{\theta^{2}}{2} t^{2 H}\right)
$$

Lemma 6 Let $f$ be a function such that $\widetilde{E}_{t}\left[f\left(\theta B_{t}^{H}\right)\right] \leq \infty$. Thus for each $t \leq T$,

$$
\widetilde{E}_{t}^{*}\left[f\left(\theta B_{T}^{H}\right)\right]=\frac{1}{X_{t}} \widetilde{E}_{t}\left[f\left(\theta B_{T}^{H}\right) X_{T}\right]
$$

Theorem 7 The price at every time $t \in[0, T]$ of a bounded $F_{T}^{H}$-measurable claim $F \in L^{2}$ as follows

$$
F_{t}=e^{-r(T-t)} \widetilde{E}_{t}[F]
$$

where $r$ shows the fixed rate of riskless interest.

\section{Pricing model}

Since, the system in finance is considered as an intricate system in investments in which investors avoid to make instant decisions after obtaining financial information in a fractional system. It means that achieving information to its threshold limit value is the major criteria for making decisions of investors rather than financial information with high flexibility. The asymmetric leptokurtic and long memory properties result from this behavior. In this regard, the beneficial model seems to be $F B M$ model.

To derive the new currency option pricing formula in a fractional market. The following hypothesis will be provided:

1. there are no transaction costs or taxes;

2. security trading is continuous;

3. The rate of domestic interest $r_{d}$ and the rate of foreign interest $r_{f}$ are known and fixed throughout time;

4. There are no riskfree arbitrage opportunities.

Now, we consider a fractional Black-Scholes currency market that has two investments: 
(a) a money market account

$$
d M_{t}=r_{d} M_{t} d t,
$$

where $r_{d}$ show the rate of domestic interest.

(b) a stock whose price satisfies the following equation:

$$
\begin{aligned}
& d S_{t}=\mu S_{t}+\sigma S_{t} d \widehat{B}_{t}^{H} \quad 0<t \leq T \quad S_{0}=S>0, \\
& \text { where } \frac{1}{2}<H<1 \text { is Hurst parameter. }
\end{aligned}
$$

Let $B_{t}^{H}=\frac{\mu+r_{f}-r_{d}}{\sigma} t+\widehat{B}_{t}^{H}$, hence respect to risk-neutral measure we have:

$$
d S_{t}=\left(r_{d}-r_{f}\right) S_{t}+\sigma S_{t} d B_{t}^{H} \quad 0<t \leq T \quad S_{0}=S>0 .
$$

Then, the solution for Eq. (13) is

$$
S_{t}=S_{0} \exp \left(\left(r_{d}-r_{f}\right) t+\sigma B_{t}^{H}-\frac{1}{2} \sigma^{2} t^{2 H}\right) .
$$

Theorem 8 The value at every $t \in[0, T]$ of a European call currency option with exercise price $K$ and expiration $T$ is given by

$$
C\left(t, S_{t}\right)=S_{t} e^{-r_{f}(T-t)} \Phi\left(d_{1}\right)-K e^{-r_{d}(T-t)} \Phi\left(d_{2}\right),
$$

where

$$
\begin{aligned}
& d_{1}=\frac{\ln \left(\frac{S_{t}}{K}\right)+\left(r_{d}-r_{f}\right)(T-t)+\frac{\sigma^{2}}{2}\left(T^{2 H}-t^{2 H}\right)}{\sigma \sqrt{T^{2 H}-t^{2 H}}} \\
& d_{2}=\sigma \sqrt{T^{2 H}-t^{2 H}} .
\end{aligned}
$$

Corollary 9 The value of European put currency option is given by

$$
P\left(t, S_{t}\right)=K e^{-r_{d}(T-t)} \Phi\left(-d_{2}\right)-S_{t} e^{-r_{f}(T-t)} \Phi\left(-d_{1}\right),
$$

where

$$
\begin{aligned}
& d_{1}=\frac{\ln \left(\frac{S_{t}}{K}\right)+\left(r_{d}-r_{f}\right)(T-t)+\frac{\sigma^{2}}{2}\left(T^{2 H}-t^{2 H}\right)}{\sigma \sqrt{T^{2 H}-t^{2 H}}} \\
& d_{2}=\sigma \sqrt{T^{2 H}-t^{2 H}} .
\end{aligned}
$$

\section{Properties of pricing formula}

Assume that $V$ is the value of currency options which depends just on $t$ and $S_{t}$. Thus, the value of whole portfolio satisfies in the partial differential equation that present in this theorem.

Theorem 10 The value of a currency options $V\left(t, S_{t}\right)$ satisfies in the following PDE

$$
\frac{\partial V}{\partial t}+H \sigma^{2} t^{2 H-1} S_{t}^{2} \frac{\partial^{2} V}{\partial S_{t}^{2}}+\left(r_{d}-r_{f}\right) S_{t} \frac{\partial V}{\partial S_{t}}-r_{d} V=0 .
$$


Now, we discuss the properties of the FBM model such as Greeks, which summarize how option prices change with respect to underlying variables that are critically important in asset pricing and risk management. In addition, it can be used to rebalance the portfolio to achieve desired exposure to a certain risk. It is significant to note that, knowing the Greek, a particular exposure can be hedged from adverse changes in the market by employing the appropriate amount of other related financial instruments. Contrary to option prices, observed in the market, Greeks can not be found and have to be calculated by a model assumption. Typically, the Greeks are computed using a partial differentiation of the price formula Shokrollahi et al. $(2015,2016)$.

Theorem 11 The Greeks can be written as

$$
\begin{aligned}
\Delta= & \frac{\partial C}{\partial S_{t}}=e^{-r_{f}(T-t)} \Phi\left(d_{1}\right), \\
\nabla= & \frac{\partial C}{\partial K}=-e^{-r_{d}(T-t)} \Phi\left(d_{2}\right), \\
\rho_{r_{d}}= & \frac{\partial C}{\partial r_{d}}=K(T-t) e^{-r_{d}(T-t)} \Phi\left(d_{2}\right), \\
\rho_{r_{f}}= & \frac{\partial C}{\partial r_{f}}=S_{t}(T-t) e^{-r_{f}(T-t)} \Phi\left(d_{1}\right), \\
\Theta= & \frac{\partial C}{\partial t}=S_{t} r_{f} e^{-r_{f}(T-t)} \Phi\left(d_{1}\right)-K r_{d} e^{-r_{d}(T-t)} \Phi\left(d_{2}\right) \\
& -S_{t} e^{-r_{f}(T-t)} \frac{\sigma H t^{2 H-1}}{\sqrt{T^{2 H}-t^{2 H}}} \Phi^{\prime}\left(d_{1}\right), \\
\Gamma= & \frac{\partial^{2} C}{\partial S_{t}^{2}}=e^{-r_{f}(T-t)} \frac{\Phi^{\prime}\left(d_{1}\right)}{S_{t} \sqrt{\sigma^{2}\left(T^{2 H}-t^{2 H}\right)}}, \\
\vartheta_{\sigma}= & \frac{\partial C}{\partial \sigma}=S_{t} e^{-r_{f}(T-t) \sqrt{T^{2 H}-t^{2 H}} \Phi^{\prime}\left(d_{1}\right) .} .
\end{aligned}
$$

The Hurst parameter $H$ play a significant role in the FBM model. Then, we represents the influence of this parameter in the following theorm.

Theorem 12 The impact of the Hurst parameter as follows

$$
\frac{\partial C}{\partial H}=S_{t} e^{-r_{f}(T-t)} \frac{\sigma\left(T^{2 H} \ln T-t^{2 H} \ln t\right)}{\sqrt{T^{2 H}-t^{2 H}}} \Phi^{\prime}\left(d_{1}\right) .
$$

Fig. 1 shows the impact of parameters on our pricing formula. 

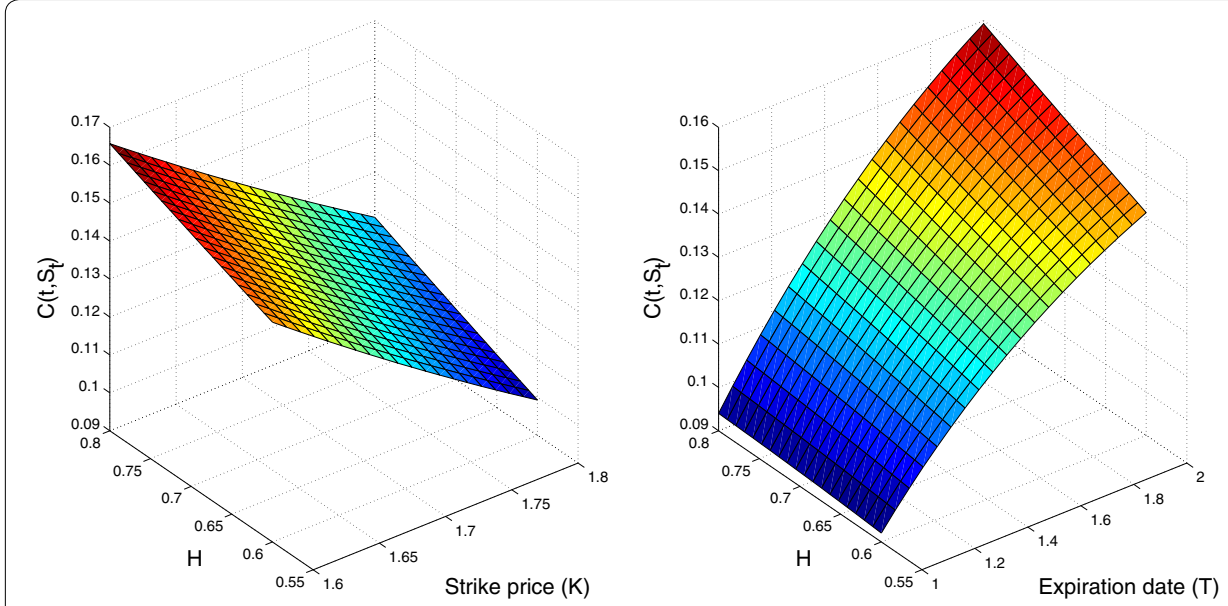

Fig. 1 European Call currency option. Parameters fixed are $r_{d}=0.321, r_{f}=0.252, \sigma=0.21, T=2, k=0.1, K=1.625, S_{t}=1.512$, and $t=0.1$

The following theorem presents the estimation of volatility by $R$ / S method.

Theorem 13 Assume $0 \leq T_{1}<T_{2}$ be given, and let a partition of this interval is chosen, $T_{1}=t_{0}<t_{1}<\cdots<t_{n}=T_{2}$. Suppose $S_{t_{i}}$ show the time series of observed price. Thus, the volatility of interval $\left[T_{1}, T_{2}\right]$ is

$$
\sigma^{2}=\frac{1}{T_{2}^{H}-T_{1}^{H}} \sum_{j=0}^{n-1}\left(\log \frac{S_{t_{j+1}}}{S_{t_{j}}}\right)^{2} .
$$

Remark 14 The relationship of call-put parity is given by

$$
C\left(t, S_{t}\right)-P\left(t, S_{t}\right)=S_{t} e^{-r_{f}(T-t)}-K e^{-r_{d}(T-t)} .
$$

Remark 15 The relationship of put-call parity satisfies

$$
\frac{\partial C\left(t, S_{t}\right)}{\partial S_{t}}-\frac{\partial P\left(t, S_{t}\right)}{\partial S_{t}}=e^{-r_{f}(T-t)} .
$$

Remark 16 The delta of spot exercise price has a space-homogeneity feature, such that for every $b>0$,

$$
b C\left(t, S_{t}\right)=b S_{t} e^{-r_{f}(T-t)} \Phi\left(d_{1}\right)-b K e^{-r_{d}(T-t)} \Phi\left(d_{2}\right),
$$

and

$$
b P\left(t, S_{t}\right)=b K e^{-r_{d}(T-t)} \Phi\left(-d_{2}\right)-b S_{t} e^{-r_{f}(T-t)} \Phi\left(-d_{1}\right) .
$$

Furthermore, differenting both sides with under $b$ and thus by $b=1$ we have

$$
C\left(t, S_{t}\right)=S_{t} \frac{\partial C\left(t, S_{t}\right)}{\partial S_{t}}+K \frac{\partial C\left(t, S_{t}\right)}{\partial K}
$$


and

$$
P\left(t, S_{t}\right)=S_{t} \frac{\partial P\left(t, S_{t}\right)}{\partial S_{t}}+K \frac{\partial P\left(t, S_{t}\right)}{\partial K} .
$$

In fact, these equation is other model of the pricing currency option, when the value of stock is measured in a various unit. Moreover, $C_{S_{t}}^{\prime}\left(t, S_{t}\right), C_{K}^{\prime}\left(t, S_{t}\right), P_{S_{t}}^{\prime}\left(t, S_{t}\right)$ and $P_{K}^{\prime}\left(t, S_{t}\right)$ can be obtained by comparing this model with Eqs. (15), (17). These methods gives a new model for calculate delta.

\section{Numerical studies}

This section deals with how implement the $F B M$ model and shows the impact of Hurst parameter $H$. In the present study, we consider the real call currency options values from Philadelphia Stock exchange $(P H L X)$ in order to investigate some information concerning our pricing formula. By applying the R/S method, we estimate the exponent parameter for EUR/USD and then we obtain $H=0.6102$. Furthermore, the volatility estimation is obtained by utilizing the historical volatility as follows;

$$
\begin{aligned}
L_{i} & =\ln \left(\frac{q_{i+1}}{q_{i}}\right), \\
\sigma & =\sqrt{\frac{\sum\left(L_{i}-\bar{L}\right)^{2}}{N-1}}, \quad \bar{L}=\frac{1}{N} \sum L_{i},
\end{aligned}
$$

where $q_{i}$ show the daily value of exchange rate.

These data are extracted from 01/06/2010 to 01/12/2010 (six months) with the following parameters:

$K=1.35, \sigma=0.1201, r_{d}=0.0231, r_{f}=0.0352, T=0.5$, and $t=0.1$. We use the MATLAB software for obtaining results by different models such as $G-K, B S$ and $F B M$ models. The values calculated by these models are represented in Table 1 , where $P_{\text {Actual }}$ indicates the price of call currency options from $P H L X$, and the $P_{B S}$ is the values computed by the $B S$ model. In addition, the $P_{F B M}$ points to the values calculated by $F B M$ model. According to Table 1 our findings are more consistent with the actual price

Table 1 Results by different pricing models

\begin{tabular}{llll}
\hline Exchange rate & $\boldsymbol{P}_{\text {BS }}$ & $\boldsymbol{P}_{\text {FBM }}$ & $\boldsymbol{P}_{\text {Actual }}$ \\
\hline 1.351 & 0.0377 & 0.0358 & 0.0338 \\
1.357 & 0.0408 & 0.0388 & 0.0362 \\
1.362 & 0.0433 & 0.0414 & 0.0391 \\
1.368 & 0.0464 & 0.0444 & 0.0423 \\
1.373 & 0.0490 & 0.0470 & 0.0456 \\
1.379 & 0.0521 & 0.0501 & 0.0484 \\
1.383 & 0.0542 & 0.0522 & 0.0503 \\
1.389 & 0.0573 & 0.0553 & 0.0537 \\
1.392 & 0.0589 & 0.0569 & 0.0548 \\
1.398 & 0.0620 & 0.0601 & 0.0589
\end{tabular}


rather than the results of the other models. These properties reveal that our FBM model is able to get the behavior from financial market, which leads to creation of a satisfactory currency pricing model.

To further understand the preference of the FBM model, we calculated the theoretical prices of the our pricing formula and then we compare it with derived results from the $G-K$ model and the $B S$ model. For our propose, these parameter valuation are selected: $r_{d}=0.0210, r_{f}=0.0320, \sigma=0.1050, t=0.1, H=0.78, S_{t}=49$ for out-of-the-money case, $S_{t}=61$ for in-the-money case with different exercise price $K \in[50,60]$ and expiration date, $T \in[0.11,20]$.

Figures 2 and 3 show the theoretical value discrepancy by the $G-K$ model, $F B M$ model and $B S$ model, for in-the- money case and out-of-the-money case, respectively. These figures reveal that our pricing model are better matched with the $G-K$ model. Then, from Table 1 and Figs. 2 and 3, we can conclude that our FBM model seems reasonable.

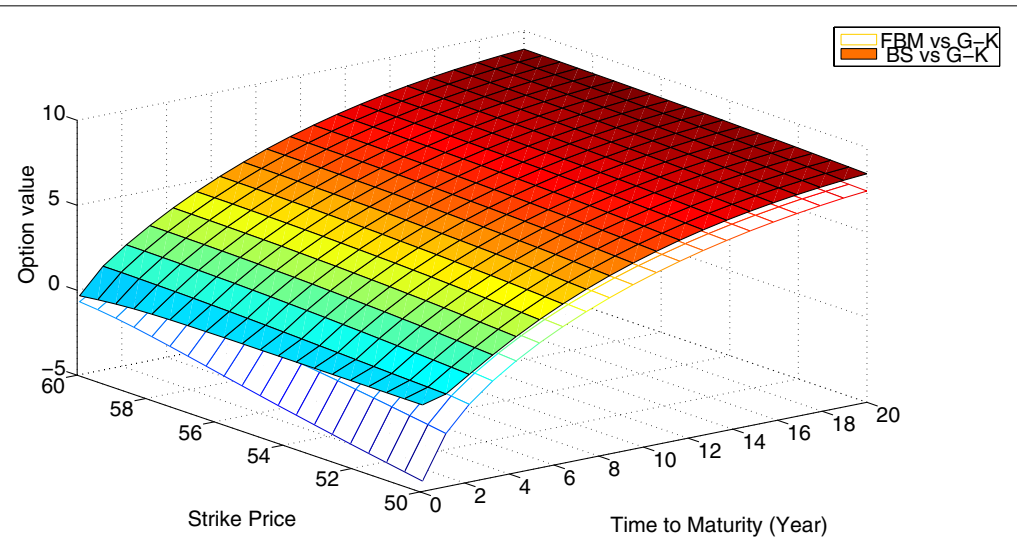

Fig. 2 Relative difference among the $G-K$ model, the FBM model and BS model in the in-the-money case

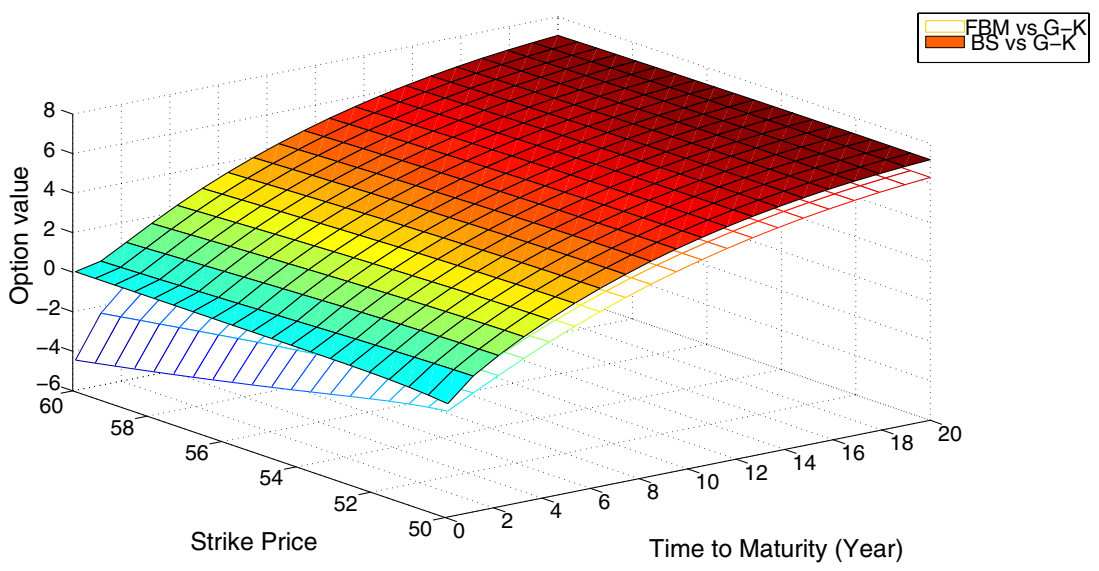

Fig. 3 Relative difference among the $G-K$ model, the FBM model and BS model in the out-of-the-money case 


\section{Conclusion}

This study provided a new framework for pricing currency options in accordance with the $F B M$ model to capture long-memory property of the spot exchange rate. In addition, a obtained a new formula for pricing European call currency options and the volatility estimation were presented. Some certain features and Greeks of currency options model are also obtained. Finally, we reported the empirical results for several models, which demonstrate that the FBM model would be reasonable.

\section{Authors' contributions}

All authors jointly worked on deriving the results. Both authors read and approved the final manuscript.

\section{Author details}

${ }^{1}$ Department of Mathematics and Statistics, University of Vaasa, 65101 Vaasa, Finland. ${ }^{2}$ Department of Mathematics, University Putra Malaysia (UPM), 43300 Serdang, Selangor, Malaysia.

\section{Acknowledgements}

The authors are very grateful to the referees for their valuable suggestions and comments that improved the paper.

\section{Competing interests}

The authors declare that they have no competing interests.

\section{Appendix}

Proof of Theorem 8 In a risk neutral world, from Theorem 7 a European call currency option with maturity $T$ and strike price $K$ can be display as

$$
\begin{aligned}
C\left(t, S_{t}\right) & =\widetilde{E}_{t}\left[e^{-r_{d}(T-t)}\left(S_{T}-K\right)^{+}\right] \\
& =e^{-r_{d}(T-t)} \widetilde{E}_{t}\left[S_{T} \mathbf{1}_{S_{T}>K}\right]-K e^{-r_{d}(T-t)} \widetilde{E}_{t}\left[\mathbf{1}_{S_{T}>K}\right] .
\end{aligned}
$$

We will first consider $\widetilde{E}_{t}\left[\mathbf{1}_{S_{T}>K}\right]$. By setting

$$
d_{2}^{*}=\ln \frac{K}{S}-\left(r_{d}-r_{f}\right) T+\frac{\sigma^{2}}{2} T^{2 H} .
$$

From Eq. (3), we have

$$
S_{t}=S_{0} \exp \left(\mu t+\sigma B_{t}^{H}-\frac{1}{2} \sigma^{2} t^{2 H}\right) .
$$

Then

$$
\begin{aligned}
\widetilde{E}_{t}\left[\mathbf{1}_{S_{T}>K}\right] & =\widetilde{E}_{t}\left[\mathbf{1}_{x>d_{2}^{*}}\left(\sigma B_{t}^{H}\right)\right] \\
& =\int_{d_{2}^{*}}^{+\infty} \frac{1}{\sqrt{2 \pi \sigma^{2}\left(T^{2 H}-t^{2 H}\right)}} \exp \left[-\frac{\left(x-\sigma B_{t}^{H}\right)^{2}}{2 \sigma^{2}\left(T^{2 H}-t^{2 H}\right)}\right] d x \\
& =\int_{\frac{d_{2}^{*}-\sigma B_{t}^{H}}{\sqrt{\sigma^{2}\left(T^{2 H}-t^{2 H}\right)}}}^{+\infty} \frac{1}{\sqrt{2 \pi}} e^{-\frac{z^{2}}{2}} d z \\
& =\int_{-\infty}^{\frac{\sigma B_{t}^{H}-d_{2}^{*}}{\sqrt{\sigma^{2}\left(T^{2 H}-t^{2 H}\right)}}} \frac{1}{\sqrt{2 \pi}} e^{-\frac{z^{2}}{2}} d z=\Phi\left(d_{2}\right) .
\end{aligned}
$$


where $z^{2}=\frac{\left(x-\sigma B_{t}^{H}\right)^{2}}{\sigma^{2}\left(T^{2 H}-t^{2 H}\right)}$, thus $x>d_{2}^{*}$ means that $z>\frac{d_{2}^{*}-\sigma B_{t}^{H}}{\sqrt{\sigma^{2}\left(T^{2 H}-t^{2 H}\right)}}$ and the last equality follows since $\sigma B_{t}^{H}=\ln \frac{K}{S}-\left(r_{d}-r_{f}\right) t+\frac{\sigma^{2}}{2} t^{2 H}$.

Now, we consider $\widetilde{E}_{t}\left[S_{T} \mathbf{1}_{S_{T}>K}\right]$; setting

$$
\sigma\left(B_{t}^{H}\right)^{*}=\sigma\left(B_{t}^{H}-\sigma t^{2 H}\right)
$$

Let

$$
X_{t}=S \exp \left(\sigma B_{t}^{H}-\frac{1}{2} \sigma^{2} t^{2 H}\right)
$$

Then we have $X_{t}=e^{-r t} S_{t}$. According to the Lemma 6, we obtain

$$
\begin{aligned}
\widetilde{E}_{t}\left[S_{T} \mathbf{1}_{S_{T}>K}\right] & =e^{r t} \widetilde{E}_{t}\left[X_{T} \mathbf{1}_{x>d_{2}^{*}}\left(\sigma B_{T}^{H}\right)\right] \\
& =e^{r t} X_{t} \widetilde{E}_{t}^{*}\left[\mathbf{1}_{x>d_{2}^{*}}\left(\sigma B_{T}^{H}\right)\right] \\
& =e^{r t} X_{t} \widetilde{E}_{t}^{*}\left[\mathbf{1}_{S_{T}>K}\right] .
\end{aligned}
$$

But

$$
\begin{aligned}
\ln S_{T} & =\ln S+\left(r_{d}-r_{f}\right) T+\sigma B_{T}^{H}-\frac{1}{2} \sigma^{2} T^{2 H} \\
& =\ln S+\left(r_{d}-r_{f}\right) T+\sigma\left(B_{T}^{H}\right)^{*}+\frac{1}{2} \sigma^{2} T^{2 H} .
\end{aligned}
$$

By setting $d_{1}^{*}=\ln \frac{K}{S}-\left(r_{d}-r_{f}\right) T-\frac{1}{2} \sigma^{2} T^{2 H}$, we obtain

$$
\begin{aligned}
\widetilde{E}_{t}^{*}\left[\mathbf{1}_{S_{T}>K}\right] & =\widetilde{E}_{t}\left[\mathbf{1}_{x>d_{1}^{*}}\left(\sigma\left(B_{t}^{H}\right)\right)^{*}\right] \\
& =\int_{d_{1}^{*}}^{+\infty} \frac{1}{\sqrt{2 \pi \sigma^{2}\left(T^{2 H}-t^{2 H}\right)}} \exp \left[-\frac{\left.\left(x-\sigma\left(B_{t}^{H}\right)\right)^{*}\right)^{2}}{2 \sigma^{2}\left(T^{2 H}-t^{2 H}\right)}\right] d x \\
& =\int_{\frac{\left.d_{1}^{*}-\sigma\left(B_{t}^{H}\right)\right)^{*}}{\sqrt{\sigma^{2}\left(T^{2 H}-t^{2 H}\right)}}}^{+\frac{1}{\sqrt{2 \pi}}} e^{-\frac{z^{2}}{2}} d z \\
& =\int_{-\infty}^{\frac{\sigma B_{t}^{H}-d_{2}^{*}}{\sqrt{\sigma^{2}\left(T^{2 H}-t^{2 H}\right)}}} \frac{1}{\sqrt{2 \pi}} e^{-\frac{z^{2}}{2}} d z=\Phi\left(d_{1}\right) .
\end{aligned}
$$

The last equality follows since

$$
\begin{aligned}
\sigma B_{t}^{H} & =\ln \frac{S_{t}}{S}-\left(r_{d}-r_{f}\right) t+\frac{1}{2} \sigma^{2} t^{2 H} \\
\sigma\left(B_{t}^{H}\right)^{*} & =\sigma\left(B_{t}^{H}-\sigma t^{2 H}\right) .
\end{aligned}
$$


Then

$$
\widetilde{E}_{t}^{*}\left[\mathbf{1}_{S_{T}>K}\right]=e^{\left(r_{d}-r_{f}\right) T} X_{t} \Phi\left(d_{1}\right)=S_{t} e^{\left(r_{d}-r_{f}\right)(T-t)} \Phi\left(d_{2}\right)
$$

Proof of Theorem 10 Let $V\left(t, S_{t}\right)$ be the price of the currency derivatives at time $t$ and let $\Pi$ be the portfolio value. Then we have

$$
\Pi_{t}=V\left(S_{t}, t\right)-\Delta S_{t}
$$

Since

$$
S_{t}=S_{0} \exp \left[\mu T+\sigma B_{T}^{H}-\frac{1}{2} \sigma^{2} T^{2 H}\right]
$$

Then

$$
\begin{aligned}
D_{u} S_{\tau} & =S_{\tau} D_{u}\left(\mu \tau+\sigma B_{\tau}^{H}-\frac{1}{2} \sigma^{2} \tau^{2 H}\right) \\
& =S_{\tau}\left[D_{u}\left(\sigma B_{\tau}^{H}\right)\right], \\
D_{u}^{\phi} & =S_{\tau} H \sigma \tau^{2 H-1} .
\end{aligned}
$$

Hence we have

$$
\begin{aligned}
d \Pi_{t}= & d V\left(t, S_{t}\right)-\Delta\left(d S_{t}+r_{f} S_{t} d t\right) \\
= & \left(\frac{\partial V}{\partial t}+H \sigma^{2} t^{2 H-1} S_{t}^{2} \frac{\partial^{2} V}{\partial S_{t}^{2}}+\mu S_{t} \frac{\partial V}{\partial S_{t}}\right) d t \\
& +\sigma S_{t} \frac{\partial V}{\partial S_{t}} d B_{t}^{H}-\Delta\left(\mu S_{t} d t+\sigma S_{t} d B_{t}^{H}+r_{f} S_{t} d t\right) \\
= & \left(\frac{\partial V}{\partial t}+H \sigma^{2} t^{2 H-1} S_{t}^{2} \frac{\partial^{2} V}{\partial S_{t}^{2}}+\mu S_{t} \frac{\partial V}{\partial S_{t}}-\Delta \mu S_{t}-\Delta r_{f} S_{t}\right) d t \\
& +\left(\sigma S_{t} \frac{\partial V}{\partial S_{t}}-\Delta \sigma S_{t}\right) d B_{t}^{H} .
\end{aligned}
$$

For eliminate the stochastic noise we choose $\Delta=\frac{\partial V}{\partial S_{t}}$, then

$$
d \Pi_{t}=\left(\frac{\partial V}{\partial t}+H \sigma^{2} t^{2 H-1} S_{t}^{2} \frac{\partial^{2} V}{\partial S_{t}^{2}}-\Delta r_{f} S_{t}\right) d t
$$

The return of an amount $\Pi_{t}$ invested in bank account equal to $r_{d} \Pi_{t} d t$ at time $d t$. For absence of arbitrage these values must be same, thus

$$
\left(\frac{\partial V}{\partial t}+H \sigma^{2} t^{2 H-1} S_{t}^{2} \frac{\partial^{2} V}{\partial S_{t}^{2}}-r_{f} S_{t} \frac{\partial V}{\partial S_{t}}\right) d t=r_{d} \Pi_{t} d t
$$

Since $\Pi_{t}=V\left(t, S_{t}\right)-\Delta S_{t}$, hence 


$$
\frac{\partial V}{\partial t}+H \sigma^{2} t^{2 H-1} S_{t}^{2} \frac{\partial^{2} V}{\partial S_{t}^{2}}-r_{f} S_{t} \frac{\partial V}{\partial S_{t}} d t=r_{d}\left(V-S_{t} \frac{\partial V}{\partial S_{t}}\right)
$$

so

$$
\frac{\partial V}{\partial t}+H \sigma^{2} t^{2 H-1} S_{t}^{2} \frac{\partial^{2} V}{\partial S_{t}^{2}}+\left(r_{d}-r_{f}\right) S_{t} \frac{\partial V}{\partial S_{t}}-r_{d} V=0 .
$$

Proof of Theorem 11 First, we derive a general formula. Let $y$ be one of the influence factors. Thus we have

$$
\begin{aligned}
\frac{\partial C}{\partial y}= & \frac{\partial S_{t} e^{-\left(r_{f}\right)(T-t)}}{\partial y} \Phi\left(d_{1}\right)+S_{t} e^{-r_{f}(T-t)} \frac{\partial \Phi\left(d_{1}\right)}{\partial y} \\
& -\frac{\partial K e^{-r_{d}(T-t)}}{\partial y} \Phi\left(d_{2}\right)-K e^{-r_{d}(T-t)} \frac{\partial \Phi\left(d_{2}\right)}{\partial y} .
\end{aligned}
$$

But

$$
\begin{aligned}
\frac{\partial \Phi\left(d_{2}\right)}{\partial y} & =\Phi^{\prime}\left(d_{2}\right) \frac{\partial d_{2}}{\partial y} \\
& =\frac{1}{\sqrt{2 \pi}} e^{-\frac{d_{2}^{2}}{2}} \frac{\partial d_{2}}{\partial y} \\
& \left.=\frac{1}{\sqrt{2 \pi}} \exp \left(-\frac{\left(d_{1}-\sqrt{\sigma^{2}\left(T^{2 H}-t^{2 H}\right)}\right)^{2}}{2}\right) \frac{\partial d_{2}}{\partial y}\right) \\
& =\frac{1}{\sqrt{2 \pi}} e^{-\frac{d_{1}^{2}}{2}} \exp \left(d_{1} \sqrt{\sigma^{2}\left(T^{2 H}-t^{2 H}\right)}\right) \exp \left(-\frac{\sigma^{2}\left(T^{2 H}-t^{2 H}\right)}{2}\right) \frac{\partial d_{2}}{\partial y} \\
& =\frac{1}{\sqrt{2 \pi}} e^{-\frac{d_{1}^{2}}{2}} \exp \left(\ln \frac{S_{t}}{K}+\left(r_{d}-r_{f}\right)(T-t)\right) \frac{\partial d_{2}}{\partial y} \\
& =\frac{1}{\sqrt{2 \pi}} e^{-\frac{d_{1}^{2}}{2}} \frac{S}{K} \exp \left(\left(r_{d}-r_{f}\right)(T-t)\right) \frac{\partial d_{2}}{\partial y} .
\end{aligned}
$$

Then we have that

$$
\begin{aligned}
\frac{\partial C}{\partial y}= & \frac{\partial S_{t} e^{-\left(r_{f}\right)(T-t)}}{\partial y} \Phi\left(d_{1}\right)-\frac{\partial K e^{-r_{d}(T-t)}}{\partial y} \Phi\left(d_{2}\right) \\
& +S_{t} e^{-r_{f}(T-t)} \Phi^{\prime}\left(d_{1}\right) \frac{\partial \sqrt{\sigma^{2}\left(T^{2 H}-t^{2 H}\right)}}{\partial y} .
\end{aligned}
$$

Substituting in (58) we get the desired Greeks. 
Proof of Theorem 12

$$
\begin{aligned}
\eta & =\frac{\partial C}{\partial H}=S_{t} e^{-r_{f}(T-t)} \Phi^{\prime}\left(d_{1}\right) \frac{\partial \sqrt{\sigma^{2}\left(T^{2 H}-t^{2 H}\right)}}{\partial H} \\
& =S_{t} e^{-r_{f}(T-t)} \Phi^{\prime}\left(d_{1}\right) \frac{\sigma\left(T^{2 H}-t^{2 H}\right)}{\sqrt{T^{2 H}-t^{2 H}}} .
\end{aligned}
$$

Proof of Theorem 13 Since

$$
S_{t}=S_{0} \exp \left(\mu t+\sigma \widehat{B}_{t}^{H}-\frac{1}{2} \sigma^{2} t^{2 H}\right)
$$

Then

$$
\log \frac{S_{t_{j+1}}}{S_{t_{j}}}=\left(\mu\left(t_{j+1}-t_{j}\right)+\sigma\left(\widehat{B}_{t_{j+1}}^{H}-\widehat{B}_{t_{j}}^{H}\right)-\frac{1}{2} \sigma^{2}\left(t_{j+1}^{2}-t_{j}^{2}\right)\right) .
$$

Hence the sum of the squares of the long return is

$$
\sum_{j=0}^{n-1}\left(\log \frac{S_{t_{j+1}}}{S_{t_{j}}}\right)^{2}=\left(\mu\left(t_{j+1}-t_{j}\right)+\sigma\left(\widehat{B}_{t_{j+1}}^{H}-\widehat{B}_{t_{j}}^{H}\right)-\frac{1}{2} \sigma^{2}\left(t_{j+1}^{2}-t_{j}^{2}\right)\right)^{2} .
$$

When the maximum step size $\|\Pi\|=\max _{j=0, \ldots, n-1}\left(t_{j}-t_{j-1}\right)$ is small. The right side of (27) is approximately equal to $\sigma^{2}\left(T_{2}^{H}-T_{1}^{H}\right)$ and then

$$
\sigma^{2} \approx \frac{1}{T_{2}^{H}-T_{1}^{H}} \sum_{j=0}^{n-1}\left(\log \frac{S_{t_{j+1}}}{S_{t_{j}}}\right)^{2} .
$$

Received: 10 April 2016 Accepted: 6 July 2016

Published online: 21 July 2016

\section{References}

Bayraktar E, Poor HV, Sircar KR (2004) Estimating the fractal dimension of the s\&p 500 index using wavelet analysis. Int J Theor Appl Finance 7(05):615-643

Bender C, Sottinen T, Valkeila E (2007) Arbitrage with fractional Brownian motion? Theory Stoch Process 13(29):23-34 Bender C, Sottinen T, Valkeila E (2008) Pricing by hedging and no-arbitrage beyond semimartingales. Financ Stoch 12(4):441-468

Björk T, Hult H (2005) A note on wick products and the fractional Black-Scholes model. Financ Stoch 9(2):197-209 Black F, Scholes M (1973) The pricing of options and corporate liabilities. J Polit Econ 81(3):637-654 Bollen NP, Rasiel E (2003) OTC currency options market. J Int Money Financ 22(1):33-64

Carbone A, Castelli G, Stanley H (2004) Time-dependent hurst exponent in financial time series. Phys A 344(1):267-271 Cheridito P (2003) Arbitrage in fractional Brownian motion models. Financ Stoch 7(4):533-553

Cookson R (1992) Models of imperfection. Risk 5(9):55-60 
Dravid AR, Richardson M, Sun T (1993) Pricing foreign index contingent claims: an application to Nikkei index warrants. J Deriv 1(1):33-51

Duan J-C, Wei JZ (1999) Pricing foreign currency and cross-currency options under garch. J Deriv 7(1):51-63

Ekvall N, Jennergren LP, Näslund B (1997) Currency option pricing with mean reversion and uncovered interest parity: a revision of the garman-kohlhagen model. Eur J Oper Res 100(1):41-59

Elliott RJ, Van der Hoek J (2003) A general fractional white noise theory and applications to finance. Math Financ 13(2):301-330

Garman MB, Kohlhagen SW (1983) Foreign currency option values. J Int Money Financ 2(3):231-237

Hu Y, Øksendal B (2003) Fractional white noise calculus and applications to finance. Infin Dimens Anal Quantum Probab Relat Top 6(1):1-32

Kwok Y, Wong H (2000) Currency-translated foreign equity options with path dependent features and their multi-asset extensions. Int J Theor Appl Financ 3(02):257-278

Mishura Y (2008) Stochastic calculus for fractional Brownian motion and related processes. Springer, Berlin

Necula C (2002) Option pricing in a fractional Brownian motion environment. SSRN 1286833

Rosenberg JV (1998) Pricing multivariate contingent claims using estimated risk-neutral density functions. J Int Money Financ 17(2):229-247

Sarwar G, Krehbiel T (2000) Empirical performance of alternative pricing models of currency options. J Future Mark 20(3):265-291

Shokrollahi F, KIlı̧man A (2014a) Pricing currency option in a mixed fractional Brownian motion with jumps environment. Math Probl Eng 2014:858210

Shokrollahi F, KIlıçman A (2014b) Delta-hedging strategy and mixed fractional Brownian motion for pricing currency option. Math Probl Eng 2014:718768

Shokrollahi F, Kllıçman A (2015) Actuarial approach in a mixed fractional Brownian motion with jumps environment for pricing currency option. Adv Differ Equ 2015(1):1-8

Shokrollahi F, Kllıçman A, Ibrahim NA, Ismail F (2015) Greeks and partial differential equations for some pricing currency options models. Malays J Math Sci 9(3):417-442

Shokrollahi F, Killçman A, Magdziarz M (2016) Pricing European options and currency options by time changed mixed fractional Brownian motion with transaction costs. Int J Financ Eng 3(1):1650003

Toft KB, Reiner E (1997) Currency-translated foreign equity options: the American case. Adv Future Opt Res 9:233-264

Wang X-T, Zhu E-H, Tang M-M, Yan H-G (2010) Scaling and long-range dependence in option pricing. II: pricing European option with transaction costs under the mixed Brownian-fractional Brownian model. Phys A 389(3):445-451

\section{Submit your manuscript to a SpringerOpen ${ }^{\circ}$ journal and benefit from:}

- Convenient online submission

$\checkmark$ Rigorous peer review

- Immediate publication on acceptance

- Open access: articles freely available online

- High visibility within the field

Retaining the copyright to your article

Submit your next manuscript at $\boldsymbol{\nabla}$ springeropen.com 